\title{
Ciudades espontáneas: seguridad y espacio público en América Latina*
}

\author{
Alexander ARAYA LÓPEZ \\ Lateinamerika-Institut \\ Freie Universität Berlin \\ alxaraya@gmail.com
}

Recibido: 04-02-2013

Aceptado: 29-06-2014

\section{RESUMEN}

Este artículo pretende introducir el debate acerca de la incompatibilidad del proyecto de la "ciudad espontánea" y la ciudad racional-normativa-hegemónica erigida en nuestras sociedades capitalistas contemporáneas, incrustadas entre procesos globales y locales. Considerando las reflexiones acerca de la ciudad y de la revolución espacial planteadas por Lefebvre, este texto resume algunas de las tendencias actuales del urbanismo y la arquitectura que apuntan a la creación de "espacios seguros" y que constituyen, de hecho, una mercancía disponible solamente para ciertos grupos afluentes de una sociedad dada. Cuestionando las soluciones ortodoxas y comerciales al problema de la delincuencia y la criminalidad en los escenarios latinoamericanos, este artículo reafirma la necesidad de una crítica amplia a los procesos de construcción y representación del crimen, a sus geografías y sus causas sociales.

Palabras clave: ciudad espontánea; criminología; geografías del crimen; espacio público; urbanismo.

\section{Spontaneous cities: Security and public space in Latin America}

\begin{abstract}
This article aims to introduce the debate about the incompatibility of the "spontaneous city" as a project and the rational-normative-hegemonic city erected in our contemporary capitalist societies, embedded in global and local processes. Considering the reflections about the city and the spatial revolution remarked by Lefebvre, this paper summaries some of the current tendencies in the urbanism and the architecture that aim to create "secure spaces" and that constitute, indeed, a new commodity available only to wealthy groups of a given society. By questioning orthodox and commercial solutions to the problem of the delinquency and the criminality in Latin American scenarios, this article reaffirms the necessity of a broad critique to the process of construction and representation of crime, its geographies and its social causes.
\end{abstract}

Key words: spontaneous city; criminology; crime geographies; public space; urbanism.

\footnotetext{
* Este artículo fue mejorado a partir de los comentarios y recomendaciones de Manuela Boatcă, Nora Garita y Estibaliz Hidalgo. La colaboración de Djan Ivson Silva fue vital para el acceso a documentales, videos y fotografías de la pixação paulista. Agradezco también las críticas y los comentarios de los dos evaluadores anónimos.
} 


\section{Cidades espontâneas: seguridade e espaço público na América Latina}

\section{RESUMO}

Este artigo pretende introduzir o debate acerca/sobre a incompatibilidade do projeto da "cidade espontânea" e a cidade racional-normativa-hegemônica fundada em nossas sociedades capitalistas contemporâneas, incrustadas entre processos globais e locais. Considerando as reflexões acerca da cidade e da revolução espacial levantadas por Lefebvre, este texto resume algumas das tendências atuais do urbanismo e da arquitetura que apontam para a criação de "espaços seguros" e que constituem, de fato, uma mecânica disponível somente para certos grupos influentes de uma dada sociedade. Questionando as soluções ortodoxas e comerciais ao problema da delinquência e da criminalidade nos cenários latinoamericanos, este artigo reafirma a necessidade de uma crítica ampla aos processos de construção e representação do crime, às suas geografias e suas causas sociais.

Palavras-chave: cidade espontânea; criminologia; geografias do crime; espaço público; urbanismo.

\section{REFERENCIA NORMALIZADA}

Araya López, Alexander (2013) "Ciudades espontáneas: seguridad y espacio público en América Latina". Geopolítica(s). Revista de estudios sobre espacio y poder, vol. 4, núm. 2, 281-304.

SUMARIO: Introducción. 1. La ciudad como proyecto de seguridad: un espacio racional y normativo. 2. La ciudad espontánea como proyecto utópico: un espacio "irracional" y multicultural. 3. La ciudad espontánea: una aproximación teórica para concluir. Bibliografia.

\section{Introducción}

Hablar de la relación entre el espacio público y la multiplicidad de fenómenos sociales de la seguridad ciudadana es una tarea casi interminable. Multiplicidad, en el sentido de que la seguridad ciudadana - referida comúnmente como inseguridad - no debe observarse exclusivamente a partir de la dimensión de la criminalidad y el delito, sino que - tanto en teoría como en la práctica- debería referirse a una matriz de seguridades (en plural); incluyendo diversos fenómenos referentes a la soberanía alimentaria, la información genética, las condiciones laborales, el acceso a educación, el respeto a la diferencia, la privacidad y la protección de datos informáticos, entre otros. Estas (in)seguridades se expresan en una igualmente diversa serie de espacios, arquitecturas, geometrías que se han diseñadoplanificado-construido-ejecutado en relación con contextos, antecedentes históricos, culturas y clases sociales específicas. Una retícula de relaciones, que en mayor o menor medida, y a partir de un enfoque tanto local como global, debe tomar en consideración la correspondiente multiplicidad de conocimientos sociales - sin priorizar ni despreciar el pensamiento académico- de forma que la realidad social sea aproximable, sensible e inteligible. 
No obstante, para los fines de este artículo, la dimensión de la seguridad ciudadana se ha restringido a la anteriormente referida realidad y percepción del delito y de la criminalidad. Con el objetivo de proponer una visión dialógica que incluya la sociología, la geografía social, la ciencia política y la criminología, este texto pretende introducir una idea simple: la ciudad espontánea es utópica en el proyecto de la urbanización total de la sociedad. Dicho de otra forma, dado que las ciudades han sido construidas con una visión racional ligada al proyecto de la sociedad capitalista - siguiendo el principio normativo de la reducción de tiempos y espacios para la producción, transporte y consumo de mercancías e informaciones (Harvey, 2001)-; las transformaciones o apropiaciones espontáneas de la ciudad por parte de sus habitantes son frecuentemente objeto de persecución, censura, control e incluso castigo (legal, económico y social). Esto ocurre principalmente debido a la priorización del principio de la ley y el orden sobre el que se asienta la seguridad ciudadana; resguardando las clases sociales dominantes y la estructura de la propiedad privada, así como las subsecuentes relaciones de poder $^{1}$ y resistencia (Foucault, 1983) ${ }^{2}$.

Si bien las ciudades corresponden a lógicas contextuales e históricas específicas y cada ciudad constituye una configuración particular y única, tanto el proceso de la urbanización total de la sociedad - siguiendo el pensamiento de Lefebvre (1972) - como las nuevas tecnologías y estrategias de la seguridad ciudadana pueden ser entendidos como tendencias normativas globales, como principios preferidos-preferibles en el diseño-planeamiento-construcción-ejecución de las urbes contemporáneas ${ }^{3}$, incluidas entre ellas las ciudades latinoamericanas. Estas tendencias pueden identificarse como $^{4}:$ 1) la emergencia de políticas de control y vigilancia del espacio público -incluyendo la "prevención del delito a través del diseño ambiental" (Crime Prevention Through Environmental Design, CPTED), el uso y empleo de cámaras de vigilancia de circuito cerrado (CCTV) o el modelo de

\footnotetext{
${ }^{1}$ Si bien puede argumentarse que todas las ciudades, tanto latinoamericanas como en otras latitudes, son ciudades espontáneas, en el sentido de que puede acontecer lo inesperado o bien que como transeúntes podemos enfrentarnos a la o el otro extraño y desconocido-desconcertante, mi apreciación de la ciudad espontánea remite a un espacio que es utilizado para una función diferente de la que originalmente fue concebido, y que incluye, no solamente la composición física de dicho espacio sino la estructura de relaciones de poder económico-político-simbólico que en dicho espacio se re-presentan o "solidifican".

${ }^{2}$ Foucault (1983: 206-226) enfatiza esta interrelación entre poder y resistencia, indicando que a través de estudio de las formas de resistencia, es posible explicar las relaciones de poder. Este artículo plantea usar el concepto de "ciudad espontánea" para referir a actos disidentes que desafían la aquí llamada ciudad racionalnormativa-hegemónica. Agradezco a un evaluador la acertada referencia a Foucault en este punto.

${ }^{3}$ En palabras de Capel (2003: 21), la forma puede resultar indiferente para la construcción de la ciudad. Por el contrario, las prácticas, normas y aspiraciones de los usuarios son insumos necesarios para aquellos que se encargan de las formas arquitectónicas.

${ }^{4}$ Como ha señalado un evaluador, es necesario mencionar que algunos de estos puntos han sido previamente abordados por los enfoques de estudios culturales (por ej., Geertz, 1973), así como por la criminología crítica (por ej., Sykes y Matza, 1957; Feinberg, 1970), que intentan relativizar tanto las motivaciones de la criminalidad así como las construcciones de las nociones de justicia y responsabilidad.
} 
criminología ortodoxa de las ventanas rotas-; 2) el consumo de soluciones de mercado para el problema de la seguridad para consumidores públicos y privados, sean empresas o individuos (tales como sistemas de seguridad, de alarma, de reconocimiento de voz, de características biométricas, la portación de armas y otros dispositivos de defensa personal, rejas, muros, perros entrenados, contratación de servicios privados de seguridad); 3) las estrategias de origen (pseudo-)comunitario (grupos de vigilancia y policías comunitarias) vinculadas con el endurecimiento de las medidas represivas-punitivas del delito y la criminalidad, así como la generación de discursos estigmatizadores, discriminatorios y de marginalización del otro diferente (por causas de origen étnico, de género, cultural o político) ${ }^{5}$.

Estos procesos, complementarios y contradictorios entre sí, constituyen un interesante punto de partida para la discusión del denominado "derecho a la ciudad" y de la ciudad como proyecto "racional" del capitalismo global. La reflexión teórica que aquí se plantea, con un intento de aproximación para la realidad social latinoamericana, consta de tres partes: una primera sección incluye fundamentos teóricos para una comprensión sociológica de la ciudad como "espacio" y como proyecto racional; un segundo apartado es dedicado a la noción de ciudad espontánea, el "derecho a la ciudad" y su carácter utópico, y, finalmente, se agrupan las principales conclusiones sobre el concepto de la ciudad espontánea acá propuesto y sobre sus limitaciones y alcances en el pensamiento social. El uso de notas periodísticas de la prensa latinoamericana e internacional ha sido incorporado con fines exclusivamente de ilustración, sin sugerir que dichos datos pueden ser generalizados para contextos globales, regionales o nacionales ${ }^{6}$.

\section{La ciudad como proyecto de seguridad: un espacio racional y normativo}

En La revolución urbana, Lefebvre (1972: 7-28) identifica el proceso histórico mediante el cual las ciudades han sido edificadas: partiendo del nacimiento de la aldea sedentaria, la ciudad surge como un proyecto político asociado a la presencia de sacerdotes, guerreros, príncipes, nobleza y jefes militares. Esta ciudad política es un centro de orden y poder, un ente administrativo, que tal como señala Lefebvre,

\footnotetext{
${ }^{5}$ Algunos de estos casos recopilados corresponden a soluciones a la criminalidad y el delito aplicadas en Europa y los Estados Unidos. Si bien dichos estudios solamente tienen conclusiones locales, podría considerarse que algunas de estas estrategias y argumentos a favor de tecnologías de seguridad (CCTV-armastoques de queda), así como algunas políticas públicas pueden migrar o difundirse en contextos latinoamericanos.

${ }^{6}$ El énfasis de este artículo es la discusión teórica del concepto de "ciudades espontáneas", por tanto, los casos incluidos ha sido seleccionados teoréticamente. Tal como han señalado los evaluadores, esto debe reforzarse con un análisis más sistemático que permita abordar la construcción de discursos de seguridad. Este esfuerzo, sin embargo, excede en mucho los límites de este artículo y de su autor.
} 
no puede ser concebido sin el rol fundamental de la escritura (documentos, órdenes, inventarios, recolección de impuestos). El comercio, ubicado en las afueras de la ciudad, en espacios caracterizados por signos de heterotopía, espacios del otro excluido y estigmatizado ${ }^{7}$ - de los sujetos de sospecha- poco a poco comienza a permear las fronteras de la ciudad política y genera un nuevo ordenamiento social: la ciudad mercantil. En esta ciudad, el intercambio comercial de mercancías se consolida como la nueva función de la urbe, con el surgimiento de una serie de formas arquitectónicas específicas subordinadas a esta lógica de producción y consumo. El ágora o el fórum, como espacios públicos de reunión, son a la vez sustituidos y suplantados por dicho mercado.

La ciudad se impone sobre el espacio rural, superando su inicial "naturaleza" de espacio insular, al mismo tiempo que es por primera vez representada simbólicamente: la imagen de la ciudad en planos abstractos y proyecciones, en coordenadas geométricas. La ciudad mercantil, según Lefebvre, es una entidad dinámica en constante transformación, que resiste en vano los embates del capital industrial; si bien señala que la industria solía ubicarse de forma estratégica en la cercanía geográfica a materias primas y fuentes de energía, el capital industrial también se acerca a las ciudades preexistentes o se instaura como arquitecto de las mismas, creándolas a necesidad. Esta urbanización es el proyecto normativo de la sociedad: disposición, orden represivo, demarcación con señales, sumarios códigos de circulación y de referencia. En dicho momento histórico, se da la implosión-explosión urbana, es decir, fenómenos de concentración urbana, de éxodo rural, de subordinación completa de lo agrario a lo urbano. En resumen: "La problemática urbana se impone a escala mundial" (Lefebvre, 1972: 21).

Este proceso de urbanización también es identificado por Harvey en sus reflexiones sobre los espacios de capital. Retomando el pensamiento marxista, Harvey (2001: 81) observa que la aniquilación del espacio por el tiempo se impone como una necesidad fundamental para el proyecto de la acumulación capitalista, con la subsecuente transformación espacial que impone configuraciones espaciales eficientes para el capital, que facilitan la circulación y la producción, el intercambio y el consumo. Harvey denomina esta configuración como "racionalidad espacial" ${ }^{\prime}$ : De esta forma, los procesos de acumulación exigen la creación de un paisaje

\footnotetext{
${ }^{7}$ Los trabajos de Richard Sennett (2002 [1977]; 1990) remarcan la relación entre el peligro que significaban estos otros diferentes y nociones de moralidad y decoro. Observa, por ejemplo, como la idea del silencio y el control de las emociones se imponen en los espacios públicos, desde el teatro hacia la calle. Históricamente, Sennett relaciona este proceso con la emergencia de espacios neutrales, orientados a integrar de forma más eficiente la diferencia. Estos espacios presentan una visión ahistórica del tiempo y rechazan la idea de la espontaneidad.

${ }^{8}$ Lo irracional remite entonces a lo que no va en sintonía con el proceso de acumulación de capital, de producción y consumo. En este sentido, los usos, transformaciones y apropiaciones espontáneas de los espacios urbanos pueden considerarse como "actos irracionales", desde la óptica del "capital".
} 
físico que sirva a la organización de la producción en todos sus aspectos: funciones especializadas de intercambio, banca, administración, planeamiento y coordinación. Es un espacio definido por la estructura jerárquica, en sincronía con los intereses económicos o políticos de los grupos dominantes. Este proceso también ocurriría en América Latina, donde el surgimiento de una lumpenburguesía se encargaría de facilitar la construcción de estructuras orientadas hacia la comunicación entre la metrópoli y los satélites - y sus economías exportadoras ${ }^{9}-$, facilitando el surgimiento de relaciones de dependencia o el lumpendesarrollo en la región (Frank, 1971)

Esta racionalidad espacial resulta tan arbitraria como la delimitación geográficaespacial-simbólica de las ciudades contemporáneas. Löw, en sus textos sobre la "sociología del espacio" (Raumsoziologie) y la "sociología de las ciudades" (Soziologie der Städte), plantea la necesidad de distinguir entre las interpretaciones absolutistas del espacio como continuo o preexistente y las interpretaciones relativistas que ven el espacio como producto de las relaciones entre "cosas"; proponiendo una aproximación crítica a la idea del espacio como un "contenedor" (Behälterraum) de "cosas": individuos, mercancías, símbolos, relaciones, entre otros (Löw, 2001). Por tanto, la ciudad puede ser interpretada más allá de su función capitalista, en donde un espacio de ordenamiento "racional" de "cosas" podría ser al mismo tiempo "otro" espacio simbólico, emotivo, cultural, histórico con una lógica no-económica, no-hegemónica, no-normativa. Considerando que la construcción del espacio es social, la "percepción" (Wahrnehmung) de un mismo lugar puede ser diferente de acuerdo con las características sociales del sujeto (o grupo) que lo observa o lo experimenta (Löw, 2001: 195). Es decir, la socialización del espacio depende de características étnicas, de género, de clase, religión, entre otros. La construcción de un espacio "inseguro", por tanto, debe seguir dicho enfoque multicultural.

El espacio, según Löw (2001: 137) en su lectura de Läpple (1991: 196-197), puede ser entendido como un "espacio-matriz" (Matrix-Raum) caracterizado por la interrelación de cuatro dimensiones: a) el "substrato de formas materiales y físicas del espacio social" (materiell-physisches Substrat gesellschaftlicher Verhältnisse); b) el rol de la estructura de clases y poder, es decir, "el espacio como causa y efecto de procesos de interacción social" (gesellschaftliche Interaktions- und Handlungsstrukturen); c) la "regulación normativa e institucional del espacio" (institutionalisiertes und normatives Regulationssystem), en el sentido de formas de propiedad y

\footnotetext{
${ }^{9}$ Este texto de Andre Gunder Frank ofrece una clara descripción histórica del surgimiento de las primitivas economías exportadoras en América Latina que funcionaron a partir de la complicidad de una lumpenburguesía local, generalmente en perjuicio del desarrollo productivo de los países satélite. La circulación de productos de actividades mineras y agropecuarias entre satélite y metrópoli es acompañada con una infraestructura de ferrocarriles, banca, mercados y otros asentamientos e instituciones que resultaron necesarios para establecer dichas relaciones de dependencia.
} 
de regulaciones legales, estéticas, de control y de comunicación; y finalmente, d) el "papel de los signos, símbolos y representaciones en la definición del comportamiento espacial" (räumliches Zeichen-, Symbol- und Repräsentationssystem). Estas dimensiones permiten debatir sobre el espacio como una construcción social en negociación, como un espacio dinámico que se transforma tanto sociocultural como históricamente.

La configuración idealista de este espacio llamado "ciudad"-"urbe"-“metrópolis" promueve la representación dominante de la uniformidad, del orden, de la limpieza, de la pulcritud (Sennett, 2002 [1977]). Sin embargo, según Thrift, las ciudades expresan además un cierto lado misantrópico, un "desprecio" por los otros habitantes de la ciudad que puede relacionarse con el temor a la vulnerabilidad, a la destrucción tanto física como simbólica de la ciudad (Thrift, 2005). Si necesitamos ciudades porque, tal como sugiere Bauman (2009:13-15), como sujetos nos encontramos atrapados en el dilema de la seguridad-libertad, esta libertad introduce anormalidades e incertidumbres en nuestra vida cotidiana, al tiempo que la seguridad como proyecto tiende a promover el equilibrio, la homogeneidad y la estabilidad necesarios para asegurar nuestra reproducción (como especie) y la reproducción misma de la "sociedad".

Es necesario enfatizar que esta "imagen de la ciudad" (Stadtbild), promovida por autoridades locales y de carácter oficial, constituye un discurso que no solamente crea identificaciones y promueve una idea de ciudad como "unidad" (Löw, 2010: 164); sino que además resulta vital para atraer inversionistas y corporaciones, no sólo con el objetivo de convertirse en ciudades creativas — basadas en el modelo de las "3T": Tecnología, Talento y Tolerancia y la clase creativa sugeridos por Florida (2002) - (Pratt, 2008); sino además en la competición global como destino turístico (Löw, 2010). Quizás el caso más evidente de este conflicto entre la "imagen de la ciudad" y la "ciudad como experiencia vivida" se refleja en la serie de desalojos forzados que han experimentado cientos de familias de favelas y otros asentamientos informales en Rio de Janeiro, en miras a la preparación de la ciudad para la Copa Mundial de Fútbol del 2014 y los Juegos Olímpicos del 2016. Los grandes beneficios económicos de dichas actividades se imponen sobre las condiciones de vida de sectores vulnerables de la población ${ }^{10}$, configurando espacios físicos y discursos. Es precisamente a partir de estos casos que se puede afirmar que el proyecto de ciudad racional-normativa-hegemónica funciona como un "guardián" (gatekeeper) de las estructuras de clase y de la propiedad privada.

\footnotetext{
${ }^{10}$ Reportaje de Amnistía Internacional publicado el 14 de Noviembre del 2011 y disponible en URL: $<$ http://www.amnesty.org/es/news/brasil-desalojos-forzosos-no-deben-empanar-olimpiadas-rio-2011-11-14>, consultado el 11 de Octubre del 2012.
} 
Desde una postura aún más radical, el pensamiento situacionista de Debord (2009: 115-116) entiende el urbanismo, el city planning, como el método mediante el cual el capitalismo - siguiendo la lógica de la dominación total- rehace los ambientes naturales y humanos. Así, el urbanismo funciona como una tecnología de separación que al fomentar una pseudocomunidad o una comunidad de individuos aislados, se encarga de salvaguardar el poder de clase y de evitar que los trabajadores - que han sido reunidos por las condiciones de la producción urbana- puedan integrarse en una verdadera comunidad. Esta idea de separación (tanto física como simbólica) puede ser ligada a la reflexión de Bauman (2007: 72-73) que señala a la emergencia de ghettos voluntarios e involuntarios; donde aquellos que se encuentran en los ghettos involuntarios y que por tal razón son percibidos como una amenaza para el resto de los habitantes, son excluidos de las mejores partes de la ciudad; mientras que aquellos que con su poder de adquisición pueden optar por separarse en un ghetto voluntario, pretenden desligar su "mundo vital" (lifeworld), o su realidad social, del mundo vital del resto de los y las habitantes. En ambas visiones, el resultado es una ciudad donde la arquitectura y el urbanismo funcionan como tecnologías de separación.

La emergencia de políticas de control y de vigilancia de los espacios públicos se ha convertido en un elemento esencial de este proceso de diseño-planeamientoconstrucción-ejecución "racional" de las urbes contemporáneas. La "prevención del delito a través del diseño ambiental" asoma como una estrategia preventiva del delito y la criminalidad a través de la intervención en las características físicas de los espacios urbanos (Kaytal, 2002; Zahm, 2007). Sus principios gestores son el incremento de la vigilancia "natural", del reforzamiento de lazos afectivos, del control natural de accesos y del mantenimiento del espacio público. Al generar espacios mejor iluminados, con sentido de pertenencia por parte de sus usuarios, así como a través del uso de diversas tecnologías - que incluyen desde la pintura anticlimb o los arbustos para dificultar el acceso a una ventana (Kaytal, 2002: 1082) hasta el diseño de asientos que desmotivan el long-sitting (Ferrell et al., 2008: 99)-, estos espacios urbanos se han convertido en una estrategia de prevención que lejos de atacar las causas de la conducta delictiva y criminal, se han impuesto como una solución de mercado que incluso podría generar nuevas modalidades de exclusión, de estigmatización y de desigualdad.

Un modelo similar surgido en los Estados Unidos, denominado la "teoría de las ventanas rotas" (Broken Windows Theory), sugiere que la presencia de una ventana rota - es decir, un elemento que se imponga como una disrupción del orden establecido- envía un mensaje de que el espacio social estaría fuera de control, lo que significaría la generación de problemáticas sociales más serias (Wilson y Kelling, 1982). Desde esta lógica, fenómenos sociales como el graffiti, la prostitución, la presencia de mendigos, de basura e incluso de jóvenes en una esquina, constituyen ventanas rotas que deben ser reparadas para garantizar la seguridad comunitaria. Este modelo, basado parcialmente en el control informal ejercido por los propios 
habitantes del espacio en cuestión, constituye una visión profundamente ortodoxa del pensamiento criminológico, donde aquellos que son estigmatizados por cuestiones étnicas, de diversidad sexual, de clase, de género, de edad, son leídos como un "otro" sospechoso y amenazante. El empleo de toques de queda, particularmente orientado hacia poblaciones juveniles en los Estados Unidos (Adams, 2003) y recientemente puesto a prueba en Bogotá ${ }^{11}$, puede entenderse como la posición más extrema de esta tendencia de retirar - físicamente- a los y las potencialmente criminales (en este caso, jóvenes) del espacio público.

El desarrollo de tecnologías como el circuito cerrado de televisión (CCTV) ha sido incorporado como parte de estas estrategias de control y de prevención -o al menos de reacción temprana- contra varias formas del delito y la criminalidad ${ }^{12}$. La implementación de esta tecnología no sólo pasa por alto las causas que generarían dichos comportamientos o prácticas delictivas y criminales, sino que además, al ser una solución de mercado disponible solamente para aquellos que pueden costearla, podría generar nuevos ordenamientos geográficos de la llamada "inseguridad". Así, el asalto que no puede ser cometido en las cercanías de un espacio que ha sido diseñado - en tanto mercancía - como un "espacio seguro", podría migrar a zonas físicamente más vulnerables de la ciudad ${ }^{13}$ (Welsh y Farrington, 2003).

Las soluciones de mercado para el problema de la delincuencia y la criminalidad son múltiples y podría decirse que son ofrecidas según la clase social del potencial consumidor: Ya sea con: a) tecnologías de separación en la forma de rejas, bardas, muros, comunidades cerradas; o con b) productos ligados más a la reacción y protección ante el ataque, como es el caso del mercado de armas de bajo calibre, espray

\footnotetext{
${ }^{11}$ Para el Día del Amor y la Amistad, celebrado el 17 de Setiembre del 2012, la alcaldía de Bogotá decidió implementar un toque de queda para menores a partir de las once de la noche, dado que, según declaraciones oficiales, el número de asesinatos y lesiones aumenta en ese día. Un nuevo toque de queda fue programado para el 31 de Octubre del 2012, fecha de la celebración de Halloween. El reportaje del diario El Espectador está disponible en su versión online: URL: <http://www.elespectador.com/noticias/bogota/articulo-374784alcaldia-recuerda-sabado-habra-toque-de-queda-menores>, consultado el 11 de Octubre del 2012. El saldo fueron 1108 menores detenidos para un fin de semana; ver URL: $<$ http://www.elnuevosiglo.com.co/articulos/9-2012-infringieron-el-toque-de-queda-1108-menores.html>, consultado el 11 de Octubre del 2012. Adams (2013) señala que este tipo de medidas no son efectivas en la prevención de la criminalidad, al menos en lo que refiere al contexto estadounidense.

${ }^{12}$ Sin duda, estas tecnologías pueden asociarse a la discusión sobre el panóptico y el control total (instituciones totales) en Foucault (2002), y posteriormente, en Agamben en su noción del dispositivo (2006). Agradezco a un evaluador por sugerir esta referencia al pensamiento de Foucault.

${ }^{13}$ En su estudio sobre comunidades en el Reino Unido y los Estados Unidos, basado en investigaciones previas sobre el tema, Welsh y Farrington (2003) concluyen que existen resultados mixtos en la difusión de los beneficios de esta tecnología tanto como en el desplazamiento de la actividad criminal hacia otros sitios. Los autores señalan la dificultad de aislar sólo los efectos resultantes de la CCTV y no de otras políticas aplicadas de forma conjunta. La tecnología CCTV, de acuerdo con sus conclusiones, parece ser particularmente efectiva en estacionamientos, con resultados no tan claros para el caso de transporte público y áreas residenciales. Welsh y Farrington también se refieren al escenario donde la presencia de cámaras en un sitio, puede traducirse en espacios seguros en sitios adyacentes que carecen de dicha tecnología.
} 
de pimienta (pepper spray, OC gas), pistolas de aturdimiento eléctrico (stun gun), sistemas de recuperación de vehículos basados en el GPS (Global Positioning System), así como con c) servicios de vigilancia privada o de guardaespaldas, ya que la industria ha convertido la seguridad ciudadana en un asunto individual -en el sentido de poder de compra - y omite los procesos sociales que son la causa originaria de las problemáticas sobre las que dicha industria de la seguridad se asienta.

Al prestar atención, por ejemplo, al caso de las armas de bajo calibre como un derecho, al menos en el contexto de los Estados Unidos, se ha argumentado que a mayor número de armas, un delincuente sería incapaz de saber si su víctima posee un arma o no, por lo que los niveles de seguridad social aumentarían para la comunidad en su conjunto ${ }^{14}$ (Kopel, 2000: 1222). Una visión más pesimista sobre la misma línea podría ser el argumentar que un delincuente, al no saber si su víctima está armada o no, es forzado a emplear más violencia y agresividad en su ataque, en vez de ser meramente "motivado" a desistir. Cabría preguntarse si en el caso de contextos del narcotráfico, como sucede con los así llamados "ajustes de cuentas" o el sicariato, estas medidas de seguridad tienen algún rol determinante en inhibir el acto criminal. Incluso en contextos latinoamericanos, como es el caso de Costa Rica, único país de la región sin ejército, el comercio de armas de bajo calibre se ha convertido en un dilema: según datos aportados por el Programa de las Naciones Unidas para el Desarrollo, el $63 \%$ de los homicidios involucran armas de fuego. Adicionalmente, 91.253 armas se encontraban registradas hasta el año 2006, con una estimación según la Fundación Arias para la Paz de tres armas en el mercado ilegal por cada arma registrada. El reporte también señala que un $38,9 \%$ de la población conoce a alguien que posee un arma — sin ser oficial de la policía o guardia privado- y que un 54,8\% considera las armas como un "mal necesario"15. La prensa también ha informado de "estrellas" o figuras del espectáculo que portan $\operatorname{armas}^{16}$, señalando además que un $98 \%$ de las y los ciudadanos que solicitan hacer

\footnotetext{
${ }^{14}$ Kopel (2000) reflexiona, a mi criterio con una visión claramente pro-armas, sobre la necesidad de comparar la legislación - en los Estados Unidos- de las armas con otros productos que producen un gran número de muertes: automóviles y alcohol. El autor argumenta que las armas tienen mejores controles legales en comparación con dichos productos y que una prohibición de las armas resultaría en la violación de un derecho constitucional (Segunda enmienda de la Constitución de los Estados Unidos).

${ }^{15}$ Reportaje del diario La Extra publicado el 21 de Febrero del 2008. La población que considera las armas como un "mal necesario" se incrementó de un $44 \%$ en el año 2004 a un 54,8\% en el 2006. Véase URL: $<$ http://www.diarioextra.com/notigex/show_news.php?subaction=showfull\&id=1203623002\&archive=1203 675649\&template>, consultado el 4 de Octubre del 2012.

${ }^{16}$ Reportaje del diario Al Día publicado el 17 de Marzo del 2009 y disponible en la versión online en URL: $<$ http://www.aldia.cr/ad_ee/2009/marzo/17/farandula1895453.html>, consultado el 4 de Octubre del 2012. El reportaje retrata diversos periodistas y humoristas de la llamada "farándula costarricense" y hace referencia al asesinato del periodista humorístico Parmenio Medina, ocurrida en julio del 2001.
} 
las pruebas psicológicas para obtener una licencia de armas las aprueban ${ }^{17}$, e incluso denunciando polígonos de tiro donde niños y niñas son entrenados en la manipulación de armas de fuego ${ }^{18}$. Cifras más recientes indican que el número de armas registrado ha crecido a 231.807 y que además cerca de 40 armas son inscritas cada día $^{19}$. Considerando estas tendencias de consumo de armas para fomentar la seguridad, la toma de decisión "personal" de armarse o desarmarse se complica a nivel individual, ya que las armas parecer ser inevitables, o incluso, podrían ser percibidas como un símbolo de estatus social.

Un último nivel de soluciones, que aparentemente ofrece una mayor participación a la ciudadanía, es el surgimiento de organizaciones de policía comunitaria o grupos de vigilancia local organizados, en donde los vecinos de una comunidad unen esfuerzos -empleando tecnologías como cámaras de seguridad o radios de comunicación- con el objetivo de mantener un cierto espacio social con bajos índices de criminalidad y delitos. Si bien esta iniciativa puede ser considerada a primera vista como positiva, dado el nivel de acción de la comunidad, al fomentar comunicación y sentido de pertenencia entre vecinos; es necesario reflexionar sobre si este proceso no refleja un traslado de responsabilidades del Estado - ya sea gobierno local o nacional- a la ciudadanía, cuando dichas tareas son parte de la responsabilidad estatal. El surgimiento de grupos de vigilantes, dispuestos a tomar la ley en sus manos, puede ser considerado como la contraparte de este proceso. Además, este tipo de iniciativas preventivas-reactivas no necesariamente tiene una incidencia en las causas de la conducta delictiva y criminal. El riesgo inherente a estas iniciativas es la emergencia de ghettos o nodos de seguridad, creando localidades seguras aisladas unas de otras, es decir, islas de seguridad.

Asociado a lo anterior, el rol de la legislación a través de penas más severas en el aparato represivo-punitivo judicial funciona como otro proceso de separación, donde aquellos que han sido considerados culpables de un delito o crimen, son separados de la comunidad por un cierto periodo de tiempo, en condiciones generalmente infrahumanas. En los contextos latinoamericanos los casos de sobrepobla-

\footnotetext{
${ }^{17}$ Editorial del periódico La Nación publicado el 25 de Octubre del 2011 y disponible en URL: $<$ http://www.nacion.com/2011-10-25/Opinion/engano-con-pruebas-psicologicas-.aspx?Page=3>, consultado el 4 de octubre del 2012.

${ }^{18}$ Reportaje del periódico La Nación publicado el día 30 de Septiembre del 2012 y disponible en URL: $<$ http://www.nacion.com/2012-09-30/Sucesos/poligonos-de-tiro-ensenan-a-menores-a-disparar-armas.aspx>, consultado el 4 de octubre del 2012.

${ }^{19}$ Editorial del periódico La Nación publicado el 16 de Octubre del 2012 y disponible en la versión online en URL: <http://www.nacion.com/2012-10-16/Opinion/armamentismo-ciudadano.aspx>, consultado el 16 de octubre del 2012.
} 
ción carcelaria ${ }^{20}$ (Dammert et al., 2010: 93-94) y las políticas de reinserciónrehabilitación que resultan cuestionables ${ }^{21}$ (Carranza, 2012) son evidentes.

Esta ciudad racional-normativa-hegemónica y orientada a la seguridad es representada a partir de mapas geográficos e indicadores de criminalidad y delincuencia que también deben ser leídos de forma crítica. En una noticia publicada por la cadena de noticias $C N N$ - basada en un estudio del Consejo Ciudadano para la Seguridad Pública y la Justicia Penal, Asociación Civil de México- se observa que las primeras veinte ciudades más violentas del mundo son latinoamericanas, nueve de ellas en México ${ }^{22}$. Además, de las cincuenta ciudades más violentas del mundo, un $90 \%(n=45)$ están situadas en el continente americano. Si bien este informe está basado en la tasa de homicidios por cada 100 mil habitantes y no representa la totalidad de delitos y crímenes, dichos datos permiten comprender por qué el tema de la seguridad ciudadana se ha convertido en una prioridad tanto regional como local. Estos mapas, tal como señala el geógrafo John Lowman (1986: 86), ofrecerían una visión distinta de la relación ciudad-suburbio si se incluyera la geografía de crímenes de cuello blanco, gubernamentales y corporativos. ¿Cómo serían estos nuevos mapas de la geografía del delito si se incluyera el ser víctima de una estafa, una mala praxis médica, un abuso físico o un chantaje por un policía u oficial de tránsito? Esta tarea analítica es parte de la de-construcción de los "espacios seguros". Incluso la distribución geográfica de los homicidios sería distinta sólo considerando la diferenciación entre crímenes de odio, crímenes pasionales, crímenes con un motivo económico, etc. Los mapas de la criminalidad y del delito responden de una cierta forma a la lógica capitalista de producción y consumo, demarcando áreas de riesgo para los "consumidores" del espacio urbano, generalmente sin proveer suficiente información contextual e histórica.

\footnotetext{
${ }^{20}$ El orden decreciente de este porcentaje de sobrepoblación carcelaria por país, según Dammert et al. (2010), serían: El Salvador 132\%, Ecuador 128\%, República Dominicana 91\%, Brasil 82\%, Chile y Bolivia 55\%, Panamá $53 \%$, Venezuela $38 \%$, Nicaragua y México 33\%, Argentina y Costa Rica 30\%, Uruguay $28 \%$, Colombia $25 \%$, Guatemala $12 \%$ y finalmente Paraguay con un 10\%. Datos para Belice, Perú, Cuba, Haití y otros países del Caribe no fueron proporcionados.

${ }^{21}$ Carranza, además de ofrecer datos más recientes sobre la sobrepoblación carcelaria, hace énfasis en la necesidad de pensar la vida posterior de los y las reclusas en términos de trabajo y educación; cuestiona las iniciativas de las cárceles privadas y su carácter orientado a las ganancias; y enfatiza la importancia del tamaño del personal carcelario necesario para ofrecer un servicio humanitario, con miras a una futura reincorporación social de los y las privadas de libertad. Un dato interesante se refiere al incumplimiento de la política de celdas individuales para las y los reclusos, en relación con las Reglas Mínimas de las Naciones Unidas para el Tratamiento de los Reclusos establecido en 1955.

${ }^{22}$ El reportaje de CCN está disponible en URL: <http://cnnespanol.cnn.com/2012/01/13/5-de-las-10ciudades-mas-violentas-del-mundo-estan-en-mexico/>, mientras que el estudio del Consejo Ciudadano para la Seguridad Pública puede ser revisado en la versión online de dicho organismo en la URL: $<$ http://www.seguridadjusticiaypaz.org.mx/biblioteca/view.download/5/145>, consultado el 18 de Noviembre del 2012.
} 
Cuando la ciudad (racional-normativa-hegemónica) se levanta como la única arquitectura posible - por tanto, como un proyecto totalitario- y en dicho proceso impone tecnologías de separación y otros mecanismos de seguridad, esta ciudad corre el riesgo de dejar de ser una ciudad para sus habitantes. Retomando las palabras de Lefebvre, la urbanización total de la sociedad, orientada a la producción y el consumo, es un urbanismo de clase puesto que:

Acompaña una decadencia, la de la ciudad espontánea y la de la urbe histórica. Implica la intervención de un poder más que la de un conocimiento. Cuando alcanza una coherencia e impone una lógica, éstas son las del Estado. Es decir, la coherencia y la lógica del vacío. El Estado sólo sabe separar, esparcir, cavar inmensos vacíos, plazas, avenidas, que son su reflejo, el de la fuerza y el de la opresión (Lefebvre, 1972: 166).

Si interpretamos la ciudad espontánea — acá solamente mencionada por Lefebvre- como un concepto sociológico, ¿cómo sería dicha ciudad espontánea?, ¿cómo se relaciona con las actuales estructuras urbanas de control y de la seguridad? Si bien antes he mencionado que la idea que este texto pretende introducir es que "la ciudad espontánea es utópica en el proyecto de la urbanización total de la sociedad", utópico debe ser entendido como una lucha por lo posible. Así, la ciudad espontánea sería el proyecto por el que se lucha desde diversos frentes, asociada a la noción del "derecho a la ciudad", de la ciudad para sus habitantes, de una ciudad que no sea misantrópica, adultocéntrica, xenófoba ni misógina, de una ciudad que sea más sostenible, más equitativa, más afectiva ${ }^{23}$.

\section{La ciudad espontánea como proyecto utópico: un espacio "irracional" y multicultural}

Cuando se piensa la ciudad como un espacio vivido, como una ciudad espontánea, es posible identificar una serie de prácticas sociales que desafían el ordenamiento racional-normativo-hegemónico orientado hacia la seguridad que es impuesto por el urbanismo, la arquitectura y el proyecto idílico de la ciudad oficial. En este sentido, espacios que han sido diseñados para una funcionalidad específica dentro de la lógica de la producción y el consumo, se ve re-apropiados y re-significados en la

\footnotetext{
${ }^{23}$ Capel (2003: 16) entiende el urbanismo como un proceso complejo y en una perspectiva menos negativa que Lefebvre, en donde la administración pública debe negociar con diferentes agentes urbanos, cada cual con sus propios intereses. La labor de la administración pública es la mediación. En mi propuesta de la ciudad espontánea, el problema resulta en esta labor de vincular los usos y transformaciones espontáneas de la ciudad con esta estructura más "rígida" de la administración pública, considerando que las ciudades y espacios urbanos son concentraciones de "diferencia".
} 
vida cotidiana de las urbes contemporáneas: la aparición de vendedores o del denominado "comercio ambulante" que utiliza parques, calles o plazas como un mercado alternativo; las transformaciones estéticas de los grafiteros, pichadores y street artists sobre edificios, puentes y otras superficies urbanas; la exploración de las cualidades acústicas de la ciudad por grupos de rappers o por la organización de fiestas ilegales, de happenings, de performance; la plantación ilegal de árboles y flores en espacios públicos (guerrilla tree planting o guerrilla gardening), así como la defensa de espacios verdes ante nuevos proyectos de corte residencial, comercial e industrial; la ocupación de estructuras abandonadas de la ciudad por movimientos como los okupa o el uso de forma alternativo de espacios físicos como en el caso de la cultura del parkour; la conquista de la calle como espacio de protesta social, de denuncia y de lucha política; la aparición de altares, cruces, y otras formas de sacralización y de duelo público desreguladas; así como otra gran diversidad de prácticas y fenómenos sociales, que son reconocibles tanto en América Latina como en Europa, Australia y Estados Unidos. Estos ejemplos hacen pensar que la ciudad espontánea es un proyecto utópico en marcha.

Si la calle, tal como indica Lefebvre (1972: 25) al citar los trabajos de Jane Jacob, es "la única seguridad posible contra la violencia criminal (robo, violación, agresión)" y "donde desaparece la calle, la criminalidad aumenta y se organiza", si es esa misma calle, que funciona como lugar de encuentros, que tiene una "función informativa, simbólica y de esparcimiento", es considerada como el espacio donde "tiene lugar el movimiento, de catálisis, sin los que no se da vida humana, sino separación y segregación, estipuladas e inmóviles", el acceso a dicha calle por parte de los habitantes constituye un derecho inviolable per se. Así, la noción del "derecho a la ciudad" ${ }^{24}$, según señala Harvey (2012: 3-4) citando a Park, consiste no solamente en el derecho de acceder a los recursos disponibles en una ciudad dada, sino también el derecho a la transformación misma de dicha ciudad. Es en este punto donde la ciudad racional-normativa-hegemónica se enfrenta irremediablemente al proyecto de la ciudad espontánea.

El empleo del término habitantes permite incluir en este "derecho a la ciudad" no solamente la llamada "ciudadanía" — término que excluye a aquellos que no se encuentran en condición de ciudadanos, tales como trabajadores migrantes ilegales, o aquéllos que por condiciones especiales requieren de otros para hacer valer sus derechos, como el caso de los jóvenes o poblaciones infantiles, poblaciones en mendicidad, entre otros-, sino que además permite superar visiones reduccionistas de la ciudadanía. En este sentido, Dagnino (2007: 553-554) defiende que la ciudadanía no puede ser reducida a una comunidad de consumidores y productores, de individuos vinculados al mercado, que deben ser tutelados por el Estado y que

\footnotetext{
${ }^{24}$ El término "derecho a la ciudad” es originalmente planteado por Lefebvre (Kofman and Lebas, 1996: 34).
} 
deben limitar su comportamiento a las formas aceptadas —es decir, normalizadaspor el gobierno y sus instituciones.

Una crítica similar ha sido planteada por Purcell al referirse a esta distinción entre habitantes y ciudadanos. Aunque Purcell (2002) señala que la idea del "derecho a la ciudad" es una alternativa radical que desafía las estructuras del capitalismo y de la ciudadanía democrático-liberal, también indica que es un concepto desconcertante en tanto que no es posible saber qué tipo de ciudad se produciría con estas nuevas políticas urbanas. Entendiendo el "derecho a la ciudad" como un derecho a acceder al centro $-\mathrm{y}$ no solamente a las periferias o al ghetto-, su tesis sugiere repensar las formas en que cada uno de los habitantes se encuentra empoderado. Con su propuesta de "políticas escalares" (scalar politics) Purcell señala la necesidad de reconfigurar la estructura democrática de forma que este "derecho a la ciudad" pueda aplicarse a nivel local, regional, nacional o global. Es decir, si las decisiones de una ciudad afectan a una ciudad "vecina", lo cual en un mundo altamente globalizado e interconectado es probable, el "derecho a la ciudad" en el sentido de participación en las decisiones sobre la ciudad debe ser considerado a partir de estas escalas. Esta misma lógica debe aplicarse a la estructura de la comunidad política, donde según su interpretación de Lefebvre, Purcell afirma la necesidad de repensar la categoría de habitante urbano como la primera escala de la participación política, independientemente de la noción de nacionalidad. Como resultado, estos procesos generarían una serie de políticas de la identidad y la diferencia, que se traducirían en la emergencia de geografías urbanas heterogéneas e híbridas.

Esta heterogeneidad de los habitantes de la ciudad ha sido también incorporada en una novedosa revisión de la teoría criminológica sugerida por Ferrell et al. (2008). Introduciendo el enfoque de la criminología cultural, como una perspectiva que se enfoque en la convergencia de procesos culturales y criminales en la vida social contemporánea, Ferrell (1999: 400) propone, a partir de Weber, la construcción de un verstehen criminológico, donde el investigador a partir de sus percepciones empáticas y subjetivas, pueda situarse dentro de la misma construcción de la "realidad" criminal. A partir de una revisión de las imágenes mediáticas de la criminalidad y del delito, del reconocimiento de agendas políticas sobre la criminalidad en el sistema de justicia, de las funciones del crimen como entretenimiento, así como del crimen no-construido - es decir, actividades y delitos que han sido omitidos de los discursos de control- esta criminología cultural superaría nociones más ortodoxas del control social.

Ferrell (1999: 403-406), en su diferenciación entre el crimen como cultura —basado en situaciones al límite, de culturas del riesgo, del peligro, de momentos de placer y de adrenalina, como sería el caso de algunas prácticas del graffiti o de las carreras de autos informales - y de la cultura como crimen - es decir, del etiquetamiento público de productos de cultura popular como prácticas criminales a partir de vías legales o de los medios de comunicación, como ha sucedido por ejemplo con los punks o con ciertos 
espacios de gay cruising - plantea la necesidad de una deconstrucción sociológica de los procesos de definición de lo criminal y lo delictivo ${ }^{25}$. La teoría del pánico moral (Cohen, 2002) evidencia la emergencia de estos discursos de estigmatización, marginalización, de descrédito y criminalización del "otro", que funciona como un chivo expiatorio o scapegoat, cuando dichos individuos o grupos constituyen una amenaza a los valores e intereses sociales. Estas campañas de pánico moral, según Hunt (1997), puede ser el resultado de las acciones de grupos de interés variados, de una ingeniería de élite o incluso podrían originarse en "grupos de base" (grassroots). Sin embargo, es necesario mencionar que, con la aparición de las nuevas tecnologías de información, tal como proponen McRobbie y Thornton (1995), los grupos víctimas de un pánico moral son hoy día relativamente menos vulnerables que en el pasado, dado que poseen mayores recursos para debatir discursivamente, ya sea a través de medios alternativos o websites, ese discurso dominante-hegemónico que pretende estigmatizarlos o criminalizarlos.

El caso de la cultura de la pixação $o^{26}$ (pichação) en São Paulo podría emplearse para comprender mejor este paradigma de la criminología cultural. Contrario a una visión más tolerante hacia el graffiti y otras formas de street art que se han impuesto como un arte y que incluso cuentan con un día nacional en Brasil (Manco et al. 2005: 14), la pixação - una caligrafía de signos o firmas negras en los edificios - ha sido estigmatizada, marginalizada y criminalizada ${ }^{27}$. La pixação enfrenta directamente la estética oficial de la ciudad y se impone con una lógica agresiva. Es una cultura que se apropia de ciertas lecturas de la criminalidad - con grupos que se autodenominan como "Los Peores" (Os Piores), "Los Tales" (Os Tais), "Cretinos" (Cretinos), etc. - a la vez que funciona como una cultura de riesgo, asociada a la adrenalina, al hedonismo y al estatus social que produce dentro del grupo de las y

\footnotetext{
${ }^{25}$ Sampson y Raudenbush (2004: 321), a partir de una cita de Stinchcombe (1963), señalan que muchas de estas actividades que producen desorden son actividades que pueden considerarse como legítimas cuando son realizadas en un espacio privado, de forma que los individuos de estatus privilegiado consiguen reducir la exposición de su desorden. Con base en este argumento, las carreras de autos, por ejemplo, pueden realizarse en pistas especiales y bajo circunstancias controladas, manteniendo su asociada "cultura de la adrenalina" casi intacta. El carácter ilegal se relacionaría con el riesgo que dicha actividad representa para otros ciudadanos o para el conductor mismo, pero dicha práctica no necesariamente constituye un crimen per se e incluso es otra actividad de consumo más, en este caso, de sectores que puedan costearse dicho "deporte", de sectores económicamente poderosos o privilegiados.

${ }^{26}$ La actividad es referida por sus creadores como "pixação" mientras que comúnmente, y particularmente en los medios de comunicación, es representada como "pichação". Esta diferencia es también un aspecto sumamente controversial y probablemente con matices identitarios. El documental "Pixo" enfatiza la primera acepción.

${ }^{27}$ Reportaje del diario Folha de São Paulo publicado el 30 de Abril Del 2011 donde se observa la diferencia en la legislación entre el graffiti (grafite, en portugués) y la pixação. URL: $<$ http://www1.folha.uol.com.br/cotidiano/909464-camara-aprova-projeto-de-lei-que-diferencia-grafite-depichacao.shtml>, consultado el 11 de Octubre del 2012.
} 
los pichadores $^{28}$. La práctica de la pixação ha exigido incluso su reconocimiento como arte, como parte integral de la cultura brasileña. Si bien es debatible que dicha práctica "invade" espacios privados y públicos y constituye un gasto para sujetos individuales, autoridades o gobiernos locales, esta visión niega los otros efectos positivos que dicha práctica pueda tener (sentido de pertenencia, desarrollo de la autoestima, denuncia social ${ }^{29}$, proceso creativo, etc.). En la televisión brasileña es posible identificar lecturas que sugieren emplear el graffiti como una rehabilitación de la pixação, considerada como meros símbolos indescifrables y sin sentido. Además, la pixação es leída como una epidemia y una peste ${ }^{30}$, que solamente puede ser combatida con campañas de higiene social que restauren el orden público. Los y las pichadores, por su parte, han resistido este proceso y han empezado a generar una serie de foros en internet, documentales, fotografías, magazines e incluso talleres ${ }^{31}$ donde puedan expresar su identidad como movimiento y su visión particular del "derecho a la ciudad".

Desde hace ya varias décadas, esta conquista de espacios - tanto físicos como simbólicos - ha sido parte del proyecto de una sociedad y un mundo diferentes por parte de una serie de públicos subalternos (new publics, counter publics, diasporic publics, deliberative publics), como señalan Fraser (1990) y Avritzer y Costa (2004), que exigen cada vez mayores derechos, no solamente en lo referente al acceso a esferas de la vida cotidiana que les eran vetadas, sino en los procesos de toma de decisiones. Estos grupos étnicos y aborígenes, de mujeres, de diversidad sexual, de personas con discapacidad física o mental, de jóvenes, de migrantes, han generado nuevos modos de subversión y de resistencia - incluida la de "desobe-

\footnotetext{
${ }^{28}$ Documental "Pixo", realizado por João Weiner y Roberto Oliveira. El documental aún no se encuentra accesible al público aunque muestras de este trabajo se han realizado en la Fundación Cartier en Paris en 2009 y en la Universität der Künste en Berlin en 2012. El investigador tuvo acceso al documental gracias a la contribución de algunos pichadores paulistas.

${ }^{29}$ Reportaje en el diario Folha de São Paulo publicado el 29 de Enero del 2012 sobre la pixação como protesta social ante el proyecto de ciudad limpia. URL: <http://wwwl.folha.uol.com.br/cotidiano/1041022sp-vive-conflito-entre-cidade-limpa-e-pichacao-protesto-diz-nyt.shtml>, consultado el 11 de Octubre del 2012.

${ }^{30}$ Reportajes del periodista Roberto Cabrini, producido por $S B T$ (Sistema Brasileiro de Televisão) y que salieron al aire los días 25 de Marzo del 2010 y 8 de Junio del 2011. Dichos reportajes se encuentran disponibles en el sitio web de Conexão Repórter en URL: <http://www.sbt.com.br/conexaoreporter/videos/>, consultado el 11 de Octubre del 2012.

${ }^{31}$ Documentales como el mencionado "Pixo", una serie de documentales auto-gestionados por Cripta Djan Ivson con el título "Sem Comédia", la recopilación fotográfica de Choque [disponible en URL: $<$ http://www.flickr.com/photos/choquephotos/sets/72157607397735248/>, consultado el 11 de Octubre del 2012], grupos en Facebook, producciones musicales autóctonas estilo rap and MC (como el caso de Grilo 13, MCPapo, Senhores Cafetões), entre otros.
} 
diencia civil" ${ }^{32}$ - con el objetivo de cerrar la brecha entre la democracia como discurso y la democracia como experiencia vivida (Guidry y Sawyer, 2003: 273). Este pluralismo contencioso, como lo denominan Guidry y Sawyer (2003: 275), sirve para resolver las contradicciones internas de los regímenes democráticos, para la creación de principios reales de equidad, de ciudadanía, de libertad y de autogobernanza.

Si la ciudad ha sido pensada como un proyecto racional-normativo-hegemónico, donde las emociones y los afectos han sido dejados en un segundo plano o limitados a aquellas emociones y afectos que pueden ser experimentados o "vividos" a partir de las soluciones ofrecidas por el mercado, es decir, a partir de productos de consumo; entonces, es evidente, tal como destaca Thrift, que las ciudades deben ser pensadas a partir de una nueva política de los afectos, como nudos emocionales (Thrift, 2005: 138), que pueden ser ligados a los cuerpos, al poder de las emociones, a la capacidad de afectar al otro y de ser afectado por el otro. Una visión similar mantiene Löw en su reflexión sobre el espacio, considerando la "lógica específica de las ciudades" (Eigenlogik der Stadt), en tanto construcción social, como un acto que no puede ser descrito cognitivamente; Löw (2010: 79) sugiere que esta lógica se establece a partir de conocimientos prácticos en rutinas, es decir, de las prácticas cotidianas del "aquí-sentirse-cómodo" y el "allí-sentirse-extraño" (Sich-hierWohlfühlens und Sich-dort-Fremdfühlens).

Si la tiranía de la opción en las sociedades contemporáneas de los países "desarrollados", tal como propone Salecl (2011), consiste en la ansiedad e incertidumbre de tener a disposición un enorme conjunto de opciones, donde cada decisión es interpretada como una "pérdida", como una mala decisión, asociada a un sentimiento de culpa y de miedo al fracaso; para el caso de la ciudad se podría sugerir una relación dialéctica entre la "tiranía de la opción" y la "tiranía de la no-opción": la ciudad solamente puede ser elegida en forma parcial. En el caso de grupos con relativo poder económico-político-simbólico, la ciudad podría convertirse en un espacio relativamente líquido, como plantea Bauman en la reflexión sobre los ghettos antes mencionada. Sin embargo, y particularmente en el caso latinoamericano, la ciudad también se impone como un espacio no-elegido, como un espacio no-optado. Ya sea por nacimiento, por migración voluntaria o forzosa, la ciudad es una estructura preexistente que permite sólo parcialmente su modificación. La élite debe lidiar con el riesgo de salir a la calle, aunque sea solamente por los escasos minutos que van de su ghetto voluntario al aeropuerto más cercano. Otros grupos menos privilegiados, en la región más urbanizada y más desigual del mundo, deben

\footnotetext{
${ }^{32}$ Esta definición de desobediencia civil se basa en la propuesta de Habermas (1996: 383) de considerarla como actos auto-referenciales en donde una regla o ley es ignorada con el objetivo de denunciar el carácter injusto de dicha regla o ley, según es percibida por aquellos envueltos en el acto de desobediencia civil.
} 
padecer la ciudad sin otra opción. La ciudad racional-normativa-hegemónica se impone como una ciudad inescapable. Es en este punto donde la ciudad espontánea - una ciudad transformada por y para sus habitantes- resulta un proyecto político de extrema importancia. En este sentido, retomando a Lefebvre:

La gran ciudad, monstruosa, tentacular, es siempre ciudad política. Constituye el medio más favorable para ejercer un poder autoritario. En este medio predominan la organización y la superorganización. La gran ciudad consagra la desigualdad. Entre el orden, difícilmente soportable, y el caos, siempre amenazante, el poder, cualquiera que sea, pero sobre todo el estatal, optará siempre por el orden. El gran problema, casi el único problema de la gran ciudad, es la cantidad. En su marco se establece necesariamente una sociedad de masas que implica la presión sobre dichas masas, la cual supone la violencia y la represión permanente. ¿Qué cabe pensar de la oposición "ciudad-campo"? Que es insuperable y que sus interacciones mutuas son catastróficas. El campo es consciente de su servidumbre frente a la ciudad, y la ciudad envenena la naturaleza, la devora, recreándola en lo imaginario para que así dure esta ilusión de actividad. El orden urbano contiene y disimula un desorden fundamental. La gran ciudad es un conjunto de vicios, poluciones, enfermedad (mental, moral y social). La alienación urbana recubre y perpetúa todas las alienaciones. En ella, y por ella, la segregación se generaliza: por clases sociales, por barrios, profesiones y edades, por etnias, por sexos. Muchedumbre y soledad. El espacio es precioso: costoso, lujo y privilegio mantenido y entretenido por una práctica (el "centro") y por las estrategias. Cierto es que la ciudad se enriquece. Atrae sobre sí todas las riquezas, monopoliza la cultura y concentra el poder. Debido a su riqueza, estalla. Cuanto más concentra los medios para vivir, más difícil para la vida. ¿La felicidad que procura la ciudad? ¿Su vida intensa? ¿La multiplicación de placeres, de opciones? Mixtificación y mitos. Si hay conexión entre las relaciones sociales y el espacio, entre los lugares y los grupos humanos, sería necesario, con el fin de establecer una cohesión, modificar radicalmente las estructuras del espacio (Lefebvre, 1972: 98-99).

\section{La ciudad espontánea: una aproximación teórica para concluir}

La ciudad espontánea, como una modificación radical de la estructura del espacio aquí definido como ciudad racional-normativa-hegemónica, en tanto que proyecto utópico en marcha, podría ser caracterizada a partir de las siguientes propuestas:

a) Es una ciudad que prioriza los afectos y las emociones sobre la maquinaria de producción y consumo de mercancías. Una ciudad pensada como experiencia vivida para sus habitantes y no como una serie de espacios insulares (el trabajo, la escuela, el centro comercial, la residencia). Un espacio social que incorpora incluso culturas del riesgo, de la adrenalina y de hedonismo, de comportamiento sociales que en de una u otro forma han 
sido considerados desviados en el proyecto moral y político de la ciudad racional-normativa-hegemónica.

b) Una ciudad que permita la emergencia de formas alternativas de organización espacial: desde la generación de estéticas alternativas hasta la incorporación de grupos de interés en las políticas urbanísticas y en el proceso de toma de decisiones sobre el espacio público. Una discusión democrática de la ciudad donde jóvenes, grupos minoritarios, poblaciones étnicas, puedan ejercer el denominado "derecho a la ciudad" -incluido entre ellos el derecho a la protesta y la desobediencia civil- sin ser objeto de criminalización o de políticas punitivas draconianas.

c) Una ciudad que funcione como una tecnología de unión en lugar de imponerse como una tecnología de separación. Esto quiere decir que la ciudad debe pensarse como una ciudad donde el conflicto es intrínseco, donde dicho conflicto sea percibido como oportunidad y no como crisis. Al promover espacios donde se genere una interacción entre los habitantes —más allá de los espacios donde se genera una comunidad de consumidores o de individuos aislados- esta nueva organización espacial podría funcionar como una invitación al diálogo, al conocimiento mutuo y a la tolerancia y respeto a la diferencia.

Si bien esta ciudad puede ser esbozada teóricamente, a partir de reformulaciones radicales de la ciudad racional-normativa-hegemónica y en miras a una mayor equidad-igualdad económico-política, existen series limitaciones operativas para la implementación de un espacio social de tales características. Si la ciudad espontánea pretende establecerse como un espacio seguro para todos y todas, el problema de los alcances de dicho proyecto surge a la vista. ¿Cómo evitar que la ciudad espontánea se vuelva un proyecto anarquista? Aunque la transformación estética de una superficie pública (a través del graffiti, de proyecciones cinematográficas, de incorporación de vegetación) puede ser considerado como "derecho a la ciudad", no puede afirmarse lo mismo cuando la demarcación de una zona hospitalaria o de un espacio para personas con discapacidad sufre una alteración que constituya un riesgo o una limitación de la calidad de vida o de la seguridad de un grupo determinado. ¿Cómo generar espontaneidad en el diseño-planeamiento-construcciónejecución de la ciudad y al mismo tiempo promover espacios seguros para todos y todas? Si bien cada grupo social, a pesar de sus diferencias irreconciliables, tendría derecho a acceder y a transformar la ciudad, existe aún el riesgo de que esta ciudad se convierta en una matriz de segmentaciones territoriales, una ghettoización de la ciudad.

¿Cómo evitar entonces los enfrentamientos - física o simbólicamente violentos- por el territorio? Esta misma debilidad es observable en relación con espacios pensados como tecnologías de unión: ¿cómo reconciliar lo irreconciliable? La ciudad espontánea, definida como lo posible, se enfrenta a la realidad de una com- 
pleja cotidianidad urbana cada vez más diversa, más multicultural, más segmentada. Una revisión de la legislación y del sistema jurídico-penal sería necesaria para descriminalizar las prácticas sociales que han sido consideradas como "crímenes" por razones de intereses de clase, de género, o políticos. La reflexión teórica sobre este proyecto - en marcha- de la ciudad espontánea, de sus manifestaciones en las urbes latinoamericanas, podría ofrecer otras respuestas y otras preguntas que contribuyan a entender la transición de esa ciudad racional-normativa-hegemónica en la que vivimos hacia la ciudad espontánea que se vislumbra como horizonte.

Implementar el "derecho a la ciudad" supondría una superación de la idea de la decisión democrática por mayoría simple, en el sentido de que los grupos en minoría numérica no sean fácilmente incorporados en una nueva estructura de dominación espacial. Una solución es la inclusión de estas llamadas minorías en los procesos de tomas de decisión, por ejemplo, a partir del derecho a decidir el uso del presupuesto público (Harvey, 2012), así como la inserción directa en la organización y administración de la ciudad (Capel, 2003). La consolidación de grupos de lectores o de televidentes de diversos orígenes sociales puede contribuir con el análisis crítico de los medios de comunicación, funcionando como un "defensor del lector", con el objetivo de desafiar discursos estereotipados o reduccionistas de espacios urbanos o de áreas específicas de la ciudad (anillos de marginación, favelas, etc.). Estas voces deben ser consideradas también en relación con discursos académicos y reportes gubernamentales que generan exclusiones y estereotipos en su construcción de "espacios seguros" (por ejemplo, mapas de criminalidad).

Si bien Lefebvre (1991: 54) enfatiza que "una revolución que no ha alcanzado la producción de un nuevo espacio es una revolución que no ha alcanzado su potencial, o que más bien, ha fracasado dado que solamente ha sustituido las superestructuras ideológicas, las instituciones y los aparatos políticos"33; es quizás necesario pensar este proceso de construcción utópica de una nueva ciudad como la construcción utópica de una nueva sociedad. Acá, la revolución mencionada por Lefebvre debería pensarse entonces como una revolución total: una alternativa radical a las estructuras de ordenamiento económico, político, espacial y simbólico que sea generada de forma espontánea. Esto significa pensar una libertad que apueste por la seguridad en dos flancos: por un lado, rechazando espacios insulares de seguridad accesibles solamente para un sector privilegiado de la población, y, por otro, que las transformaciones y usos espontáneos del espacio público urbano no sean considerados "crímenes" per se, sino que los productores de estos espacios alternativos (no

\footnotetext{
${ }^{33}$ Mi traducción. Referencia original: "A revolution that does not produce a new space has not realized its full potential; indeed it has failed in that it has not changed life itself, but has merely changed ideological superstructures, institutions or political apparatuses."
} 
hegemónicos) sean copartícipes en la definición y construcción de "espacios seguros".

\section{Bibliografía}

Adams, Kenneth (2003) "The Effectiveness of Juvenile Curfews in Crime Prevention". Annals of the American Academy of Political and Social Science. vol. 587, 136-159.

Agamben, Giorgio (2006) Che cos'è un dispositivo. Roma: Nottetempo.

Avritzer, Leonardo, y Costa, Sérgio (2004) "Teoria crítica, democracia e esfera pública: Concepções e usos na America Latina”. Dados, vol. 47, núm. 4, 703728

[URL:

$<$ http://redalyc.uaemex.mx/src/inicio/ArtPdfRed.jsp?iCve=21847403 $>$, consultado el 1 de Febrero de 2012].

Bauman, Zygmunt (2007) Liquid Times. Cambridge: Polity Press.

Bauman, Zygmunt (2009) Does Ethics have a Chance in a World of Consumers? Cambridge: Harvard University Press.

Carranza, Elías (2012) "Situación penitenciaria en América Latina y el Caribe ¿Qué hacer?" Anuario de Derechos Humanos, vol. 3, 1-66 [URL: $<$ http://www.anuariocdh.uchile.cl/index.php/ADH/article/view/20551/21723>, consultado el 4 de Octubre del 2012].

Capel, Horacio (coord.) (2003) Ciudades, arquitectura y espacio urbano (Serie "Mediterráneo Económico", n 3). Almería: Instituto de Estudios de Cajamar.

Cohen, Stanley (2002) Folk Devils and Moral Panics. London: Routledge.

Dagnino, Evelina (2007) "Citizenship: A Perverse Confluence". Development in Practice, vol. 17, núm. 4/5, 549-556.

Dammert, Lucía et al. (2010) Crimen e inseguridad: indicadores para las Américas.

Santiago: FLACSO-Chile/Banco Interamericano de Desarrollo (BID).

Debord, Guy (2009) Society of the Spectacle. Sussex: Soul Bay Press Ltd.

Feinberg, Joel (1970) Doing and Deserving. Essays in the Theory of Responsibility.

New Jersey: Princeton University Press.

Ferrell, Jeff (1999) "Cultural Criminology”. Annual Review of Sociology, vol. 25, 395-418.

Ferrell, Jeff et al. (2008) Cultural Criminology. London: SAGE Publications.

Florida, Richard (2002) "The Economic Geography of Talent". Annals of the Association of American Geographers, vol. 92, núm. 4, 743-755. 
Foucault, Michel (1983) "The Subject and Power", en H. Dreyfus y P. Rabinow (eds.) Michael Foucault: Beyond Structuralism and Hermeneutics. Chicago: The University of Chicago Press.

Foucault, Michel (2002) Vigilar y castigar: nacimiento de la prisión. Argentina: Siglo XXI Editores.

Frank, Andre Gunder (1971) Lumpenburguesía: Lumpendesarrollo. México: Era.

Fraser, Nancy (1990) "Rethinking the Public Sphere: A Contribution to the Critique of Actually Existing Democracy". Social Text, núm. 25/26, 56-80.

Geertz, Clifford (1973) The interpretation of cultures. New York: Basic Books.

Guidry, John A., y Sawyer, Mark Q. (2003) "Contentious Pluralism: The Public Sphere and Democracy". Perspectives on Politics, vol. 1, núm. 2, 273-289.

Habermas, Jürgen (1996) Between Facts and Norms: Contributions to a Discourse Theory of Law and Democracy [Trad. por W. Rehg]. Cambridge: MIT Press.

Harvey, David (2001) Spaces of Capital. Towards a Critical Geography. Edinburgh: Edinburgh University Press.

Harvey, David (2012) Rebel Cities. From the Right to the City to the Urban Revolution. London: Verso.

Hunt, Arnold (1997) "«Moral Panic» and Moral Language in the Media"._The British Journal of Sociology, vol. 48, núm. 4, 629-648.

Kaytal, Neal Kumar (2002) "Architecture as Crime Control”. The Yale Law Journal, vol. 111, núm. 5, 1039-1139.

Kopel, David B. (2000) "Treating Guns like Consumers Products". University of Pennsylvania Law Review, vol. 148, núm. 4, 1213-1246.

Läpple, Dieter (1992) "Essay über den Raum. Für ein gesellschaftliches Raumkonzept", en H. u. A. Häußermann (Hg.) Stadt und Raum. Pfaffenweiler: Centaurus-Verl.-Ges, 157-207

Lefebvre, Henri (1972) La revolución urbana. Madrid: Alianza Editorial.

Lefebvre, Henri (1991) The production of space. Oxford y Cambridge: Blackwell.

Lowman, John (1986) "Conceptual Issues in the Geography of Crime: Toward a Geography of Social Control". Annals of the Association of American Geographers, vol. 76, núm. 1, 81-94.

Löw, Martina (2001) Raumsoziologie. Frankfurt am Main: Suhrkamp.

Löw, Martina (2010) Soziologie der Städte. Frankfurt am Main: Suhrkamp.

Manco, Tristan et al. (2005) Graffiti Brasil. London: Thames \& Hudson Ltd.

McRobbie, Angela, y Thornton, Sara L. (1995) "Rethinking «Moral Panic» for Multi-Mediated Social Worlds". The British Journal of Sociology, vol. 46, núm. 4, 559-574.

Pratt, Andy C. (2008) "Creative Cities: The Cultural Industries and the Creative Class”._Geografiska Annaler. Series B, Human Geography, vol. 90, núm. 2, 107117.

Purcell, Mark (2002) "Excavating Lefebvre: The Right to the City and its Urban Politics of the Inhabitant". GeoJournal, vol. 58, núm. 2-3, 99-108. [URL: 
$<$ http://faculty.washington.edu/mpurcell/geojournal.pdf $>$, consultado el 4 de Octubre de 2012].

Sampson, Robert J., y Raudenbush, Stephen W. (2004) "Seeing Disorder: Neighborhood Stigma and the Social Construction of «Broken Windows»". Social Psychology Quarterly, vol. 67, núm. 4, 319-342.

Salecl, Renata (2011) The tyranny of choice. London: Profile Books.

Sennett, Richard (1990) The Conscience of the Eye: The Design and Social Life of Cities. New York: Alfred A. Knopf.

Sennett, Richard (2002) The Fall of the Public Man. London: Penguin Books.

Stinchcombe, Arthur L. (1963) "Institutions of Privacy in the Determination of Police Administrative Practice". American Journal of Sociology, vol. 69, núm. 2, $150-160$.

Sykes, Gresham M., y Matza, David (1957) "Techniques of Neutralization: A Theory of Delinquency". American Sociological Review, vol. 22, núm. 6, 664670.

Thrift, Nigel (2005) "But Malice Aforethought: Cities and the Natural History of Hatred". Transactions of the Institute of British Geographers, New Series, vol. 30, núm. 2, 133-150.

Wilson, James Q., y Kelling, George L. (1982) "Broken Windows". The Atlantic Magazine

$<$ http://www.theatlantic.com/magazine/archive/1982/03/brokenwindows/304465>, consultado el 23 de Agosto del 2011].

Welsh, Brandon C., y Farrington, David P. (2003) "Effects of Closed-Circuit Television on Crime". Annals of the American Academy of Political and Social Science, vol. 587, 110-135.

Zahm, Diane (2007) Using Crime Prevention Through Environmental Design in Problem-Solving (U.S. Department of Justice: Problem-Oriented Guides for Police Series, núm. 8) [URL: $<$ http://www.cops.usdoj.gov/Publications/e0807391.pdf $>$, consultado el 19 de Junio de 2012]. 